\title{
Tracking mesoscale convective systems in the Sahel: relation between cloud parameters and precipitation
}

\author{
Goyens Clemence, ${ }^{a}$ Lauwaet Dirk, ${ }^{\mathrm{a}}$ Van Lipzig Nicole, ${ }^{\mathrm{a}}$ Schröder Marc ${ }^{\mathrm{b}}$ \\ and Demuzere Matthias ${ }^{\mathrm{a}}$ \\ a Physical and Regional Geography Research Group, Katholieke Universiteit Leuven, Celestijnenlaan 200 E, 3001 Leuven, Belgium \\ b Satellite Application Facility on Climate Monitoring, Deutscher Wetterdienst, Frankfurter Straße 135, 63067 Offenbach, Germany
}

\begin{abstract}
Although mesoscale convective systems (MCSs) are the main source of precipitation in the semi-arid Sahel region, the relationship between MCS characteristics and their generated precipitation remain unclear. However, a thorough understanding of this relation is essential to work towards a classification scheme for MCSs and eventually to improve quantitative precipitation estimates in which cloud parameters are used as proxy yariables for the total or maximum intense rainfall from a system. Accordingly, this study aims to analyse the cloud parameters and rain variables distributions and their concurrence before quantifying the relationships between them. This is done using hourly EUMETSAT's Meteosat- 8 infrared $(10.8 \mu \mathrm{m})$ images, 3-hourly precipitation data from •NASA's Tropical Rainfall Measuring Mission and an MCS tracking algorithm. The period of interest extends from 1 June till 22 September 2006 and the area of interest covers the Lake Chad region. Results indicate that MCSs in the Sahel region generally show a maximum cloud coverage around $57000 \mathrm{~km}^{2}$, a life duration of $9 \mathrm{~h}$, an embedded convective core during $6 \mathrm{~h}$ and precipitation peaks around $12.3 \mathrm{~mm} \mathrm{~h}^{-1}$. A recurrent sequence of cloud and rain variables is also noticed; maximum in cloud coverage is mostly preceded by a minimum in brightness temperature in the cold convective core and is followed by a peak in precipitation. Longer-lived and larger MCSs as well as MCSs embedding very cold and long-lived convective cores exhibit an increased likelihood to induce more intense precipitation. Focussing on the characteristics of the cold convective core rather than on the characteristics of the entire system appears to be more relevant to predict the precipitation as the former are better correlated with the generated precipitation and can be used as proxy parameter for estimations of maximum intense precipitation using two-dimensional nonlinear regression models. Copyright (c) 2011 Royal Meteorological Society
\end{abstract}

KEY WORDS mesoscale convective systems; Sahel; meteosat; TRMM; precipitation

Received 18 March 2010; Revised 29 April 2011; Accepted 21 June 2011

\section{Introduction}

In the tropics and mid-latitudes, heavy precipitation is closely related to convective activity accounting for a large proportion of the rainfall. These systems, known as mesoscale convective systems (MCSs), are defined as an ensemble of strong convective cells accompanied by a stratiform region evolving into organized clusters and forming a single mesoscale cloud. In the Sahel region, MCSs represent the main source of rainfall (Laurent et al., 1998; Mathon et al., 2002). Given the existing tendency for drought and desertification in vulnerable regions such as the Sahel, the study of features governing MCSs is essential in order to have a better understanding of the rainfall variability. Numerous studies already investigated the spatial distribution, the diurnal and interannual variability and the life cycle of MCSs (Desbois et al., 1988; Machado et al., 1992; Laing and Fritsch, 1993; Mathon and Laurent, 2001; Mathon et al., 2002;

* Correspondence to: Goyens Clemence, Université du Littoral-Côte d'Opale, Laboratoire d'Océanologie et de Géosciences (LOG), MREN, 32 avenue Foch, 62930 Wimereux, France.

E-mail: clemence.goyens@univ-littoral.fr
Schröder et al., 2009). These studies concluded that MCSs are initiated preferentially in the mid-afternoon and dissipate in the evening or early morning (Desbois et al., 1988; Laing and Fritsch, 1993; Mathon and Laurent, 2001). Orography also seems to play a key role in the initiation and propagation of MCSs (Laing et al., 2008; Schröder et al., 2009). In the Sahel, most of the MCSs propagate westwards and their velocity increases when their lifetime is long (Mathon and Laurent, 2001). Previous research also concluded that cloud area, life duration (LD) and propagation speed are positively related to the induced precipitation (Laurent et al., 1998; Mathon et al., 2002).

Geostationary weather satellite images have been proven to be appropriate for the tracking of MCSs. These satellite images allow the observation of ever-changing large-scale weather events thanks to their high temporal resolution and large field of view. Generally, infrared (IR) radiance images are converted into brightness temperature (BT) and deep convection, characterized by high cloud tops, can be identified by low BTs. The strong contrast between the cold cloud tops and the warmer background further aid in the identification and tracking 
Table I. Non-exhaustive overview of data sets, BT threshold values, area cut-off's and minimum LD criteria used for the tracking of MCSs in previous studies.

\begin{tabular}{|c|c|c|c|}
\hline \multirow[t]{2}{*}{ Sources } & \multicolumn{2}{|c|}{ Materials } & \multirow{2}{*}{$\begin{array}{l}\text { Thresholds and cut-off } \\
\text { area channels }\end{array}$} \\
\hline & Satellite $(\Delta x$ and $\Delta t)$ & Channels & \\
\hline Klitch et al. (1985) & GOES-5 & IR and VIS & $\begin{array}{l}\leq 233 \mathrm{~K} \text { and bright appearance } \\
\text { in VIS }\end{array}$ \\
\hline Desbois et al. (1988) & $\begin{array}{l}\text { METEOSAT ISCCP } \\
(30 \mathrm{~km}, 3 \mathrm{~h})\end{array}$ & $\begin{array}{l}\text { IR }(10.5-12.5 \mu \mathrm{m}) \text { and } \\
\text { WV }(5.7-7.1 \mu \mathrm{m})\end{array}$ & $\leq 233 \mathrm{~K}$ \\
\hline Machado et al. (1992) & $\begin{array}{l}\text { METEOSAT ISCCP } \\
(30 \mathrm{~km}, 3 \mathrm{~h})\end{array}$ & $\begin{array}{l}\text { IR }(10.5-12.5 \mu \mathrm{m}) \text { and } \\
\text { VIS }(0.4-1.1 \mu \mathrm{m})\end{array}$ & $\leq 233$ and $\leq 213 \mathrm{~K}$ \\
\hline Arnaud et al. (1992) & $\begin{array}{l}\text { METEOSAT }(5 \mathrm{~km} \text {, } \\
30 \mathrm{~min})\end{array}$ & IR $(10.5-12.5 \mu \mathrm{m})$ & \\
\hline $\begin{array}{l}\text { Hodges and Thorncroft } \\
\text { (1997) }\end{array}$ & $\begin{array}{l}\text { METEOSAT ISCCP } \\
(150 \mathrm{~km}, 3 \mathrm{~h})\end{array}$ & IR $(10.5-12.5 \mu \mathrm{m})$ & $\leq$ \\
\hline Laurent et al. (1998) & METEOSAT $(5 \mathrm{~km}, 3 \mathrm{~h})$ & IR $(10.5-12.5 \mu \mathrm{m})$ & $\begin{array}{l}\leq 233 \text { and } 213 \mathrm{~K} \text {, area cut-off }= \\
500 \mathrm{~km}^{2}\end{array}$ \\
\hline Nuret and Chong (1998) & GMS-4 (5 km, $1 \mathrm{~h})$ & IR $(10.5-12.5 \mu \mathrm{m})$ & $\leq 273, \leq 235$ and $\leq 208 \mathrm{~K}$ \\
\hline Machado et al. (1998) & $\begin{array}{l}\text { GOES-7 ISCCP (30 km, } \\
3 \mathrm{~h})\end{array}$ & $\operatorname{IR}(\sim 11 \mu \mathrm{m})$ & $\leq 245$ and $\leq 218 \mathrm{~K}$ \\
\hline $\begin{array}{l}\text { Carvalho and Jones } \\
\text { (2001) }\end{array}$ & GOES-8 (4 km, $1 \mathrm{~h})$ & $\operatorname{IR}(\sim$ & $\begin{array}{l}\leq 235 \mathrm{~K}, \text { minimum radius }= \\
100 \mathrm{~km}\end{array}$ \\
\hline Mathon et al. (2002) & $\begin{array}{l}\text { METEOSAT }(5 \mathrm{~km} \text {, } \\
30 \mathrm{~min})\end{array}$ & IR $(10.5-12.5 \mu \mathrm{m})$ & $\begin{array}{l}\leq 253, \leq 233, \leq 213 \mathrm{~K} \text { and area } \\
\text { cut-off }=5000 \mathrm{~km}^{2}\end{array}$ \\
\hline Laurent et al. (2002) & $\begin{array}{l}\text { GOES- } 8(4 \mathrm{~km} \text { and } \\
30 \mathrm{~min})\end{array}$ & $\operatorname{IR}(\sim 1$ & $\begin{array}{l}\leq 253, \leq 210 \mathrm{~K} \text { and area cut-off } \\
=3500 \mathrm{~km}^{2}\end{array}$ \\
\hline Mathon et al. (2002) & $\begin{array}{l}\text { METEOSAT }(5 \mathrm{~km} \text {, } \\
30 \mathrm{~min})\end{array}$ & $\operatorname{IR}(10.5-12.5 \mu \mathrm{m})$ & $\begin{array}{l}\leq 233, \leq 213 \mathrm{~K}, \text { area cut-off }= \\
5000 \mathrm{~km}^{2} \text { and life cycle }>3 \mathrm{~h}\end{array}$ \\
\hline Wilcox (2003) & $\begin{array}{l}\text { METEOSAT }(5 \mathrm{~km} \text {, } \\
30 \mathrm{~min})\end{array}$ & $\begin{array}{l}\text { IR }(10.5-12.5 \mu \mathrm{m}) \text { and } \\
\text { WV }(5.7-7.1 \mu \mathrm{m})\end{array}$ & $\leq 240 \mathrm{~K}$ \\
\hline $\begin{array}{l}\text { Machado and Laurent } \\
\text { (2004) }\end{array}$ & $\begin{array}{l}\text { GOES- } 8(4 \mathrm{~km} \text { and } \\
30 \mathrm{~min})\end{array}$ & $\operatorname{IR}(\sim 11 \mu \mathrm{m})$ & $\begin{array}{l}\leq 235,210 \mathrm{~K} \text { and area cut-off } \\
=3500 \mathrm{~km}^{2}\end{array}$ \\
\hline $\begin{array}{l}\text { Feidas and Cartalis } \\
\text { (2005) }\end{array}$ & $\begin{array}{l}\text { METEOSAT }(5-6.5 \mathrm{~km} \text {, } \\
30 \mathrm{~min})\end{array}$ & WV $(5.7-7.1 \mu \mathrm{m})$ & $\leq 233 \mathrm{~K}$ \\
\hline Tomasini et al. (2006) & $\begin{array}{l}\text { METEOSAT }(5 \mathrm{~km} \text {, } \\
30 \mathrm{~min})\end{array}$ & IR $(10.8 \mu \mathrm{m})$ & $\begin{array}{l}\leq 233 \mathrm{~K} \text {, and area cut-off }= \\
5000 \mathrm{~km}^{2}\end{array}$ \\
\hline $\begin{array}{l}\text { Futyan and Del Genio } \\
(2007)\end{array}$ & $\begin{array}{l}\text { METEOSAT (smoothed } \\
\text { to } 45 \mathrm{~km}, 1 \mathrm{~h} \text { ) }\end{array}$ & IR & $\begin{array}{l}\text { Large deep systems }=\mathrm{BT}_{\min } \\
200 \mathrm{~K} \text { and radius } 300 \mathrm{~km} \text { for } \\
\mathrm{BT} \leq 254 \mathrm{~K}\end{array}$ \\
\hline Laing et al. (2008) & $\begin{array}{l}\text { METEOSAT ( } 5 \mathrm{~km} \text {, } \\
30 \mathrm{~min})\end{array}$ & IR $(11.5 \mu \mathrm{m})$ & $\leq 23 \overline{3} \mathrm{~K}$ \\
\hline Schröder et al. (2009) & $\begin{array}{l}\text { METEOSAT }(3 \mathrm{~km} \text { and } \\
15,30 \text { and } 60 \mathrm{~min})\end{array}$ & $\begin{array}{l}\text { IR }(10.8 \mu \mathrm{m}) \text { and WV } \\
(6.2 \mu \mathrm{m})\end{array}$ & $\begin{array}{l}\leq 230 \mathrm{~K} \text { and area cut-off }= \\
900 \mathrm{~km}^{2}\end{array}$ \\
\hline
\end{tabular}

of MCSs (Kidder and Vonder Haar, 1995). Table I shows an overview of the BT thresholds, area cut-off and minimum LD used in previous studies for the tracking of MCSs. As there is no universal definition of MCSs for tracking, tracking parameters and thresholds are chosen as a function of the study area, period of interest and objectives of the research.

The diurnal cycle of precipitating features, as well as the contribution of MCSs in the tropical rainfall budget and the relationship between average and/or total rainfall and MCS characteristics, have been the focus of several studies in the past (Sui et al., 1997; Laurent et al., 1998; Laing et al, 1999; Nesbitt et al., 2000; Mathon et al., 2002; Mohr, 2004). However, the investigation of the direct relationships between cloud parameters (e.g. maximum area, minimum BT, LD) and rainfall peaks, based on data retrieved from remote sensing devices, remains poor. Although it is essential to take rainfall peaks generated by deep convection into account as they may be destructive by nature and may be a limiting factor for agriculture and subsequently reduce food security. This is particularly true in sub-saharan Africa where the total rainfall is less than in Indonesia and equatorial South-America but the storms are more intense (Zipser et al., 2006; Geerts and Dejene, 2007). Moreover, a better understanding of the relationships between cloud parameters and rain variables may contribute in reducing the scarcity of rainfall variables in remote areas such as the Sahel using cloud parameters as proxy variables. Indeed, the latter are more easily estimated based on remote sensing images provided by, among others, geostationary satellites. Futyan and Del Genio (2007) 
1 already aimed to relate the life cycle stage of the sys2 tems with the precipitating area fraction and average rain 3 rate by matching Tropical Rainfall Measurement Mis4 sion (TRMM) and Meteosat IR images over the African continent and Tropical Atlantic (Table I). However, the authors did not investigate the relationships between the structural and radiative cloud parameters and the rain variables. Therefore, our study complements well Futyan and Del Genio's (2007) work.

Accordingly, this study aims to test several hypotheses: (1) there is a clear daily cycle in initiation and dissipation of an MCS, (2) a recurrent sequence of the cloud parameters and rainfall variables exists over the life time of a system and (3) relationships exist between the cloud parameters of an MCS and the rain associated with such a system. If these hypotheses are confirmed, the data will be used to quantify the daily cycle, the sequence over the life time of the MCS and the relation between cloud and rain parameters of an MCS.

The structure of the article is as follows: The next section explains the data and methods used to track and assess the cloud parameters and relate these to the maximum intense precipitation. In Section 3.1, we investigate the distribution of the maximum cloud area, LD, propagation speed, maximum intense rainfall and other radiative properties of the tracked MCSs. Section 3.2 provides an overview of the diurnal cycles of the rain season MCSs in the Sahel and how rain variables and cloud parameters occur following recurrent sequences during the life cycle of the systems. Section 3.3 discusses the relationships, quantified by rank correlation coefficients and two-dimensional (2D) nonlinear regression models, between cloud parameters and maximum intense precipitation. The hypothesis that longer-lived, deeper and fast-moving systems are more likely to induce heavy precipitation is also investigated in this section. The article is finally wrapped up with a conclusion.

\section{Data and methods}

This study focuses on MCSs tracked during the core of the rain season of 2006 (between 1 July and 22 September) in the Sahelian region centred on Lake Chad extending from $0-30^{\circ} \mathrm{E}$ and from $5-20^{\circ} \mathrm{N}$. This region includes the West African band between 10 and $15^{\circ} \mathrm{N}$, characterized as a region of maximum activity in deep convection modulated by the strong vertical wind shear near $700 \mathrm{hPa}$ (Chong et al., 1987). MCSs are identified on successive hourly Meteosat- 8 images (with a spatial resolution of $3.1 \mathrm{~km}$ at Sub Satellite Point) assuming that strong convective activity is related to low BT. Tracking the systems is performed using an algorithm developed by Schröder et al. (2009) based on the assumption that an MCS does not vary much in area and position between two successive images. An overlap criterion, defined as the percentage of cloud area shared by two systems between two successive images, is used to assign systems in time. This criterion is chosen as a function of the area cut-off and temporal resolution of the data set (here defined like Schröder et al. (2009) as 5\% which is considered small enough for tracking fast-moving systems). Furthermore, it allows the identification of merger and split events. Beside the overlap criterion, automatically tracking of MCSs on IR images also requires several additional tracking criterion such as minimum area and life cycle and maximum BT. In this research, the latter are defined based on a visual inspection of the systems on the Meteosat and TRMM images as well as on the literature outlined in Table I.

Figure 1 gives a schematic overview of the tracking algorithm and selection criteria for the identification of MCSs. As indicated by the first decision criteria (upper-right grey box in Figure 1) the tracking algorithm first identifies pixels with BT below $233 \mathrm{~K}$. Next, the algorithm starts tracking any system as soon as it presents a contiguous area of pixels with BT below $233 \mathrm{~K}$ of at least $3500 \mathrm{~km}^{2}$. This threshold was chosen following the studies of Laurent et al. (2002) and Machado and Laurent (2004) who showed that with an area cut-off equal to $5000 \mathrm{~km}^{2}$ the time at dissipation and initiation is close to what could be achieved by manual tracking. After, the algorithm searches for potential forerunners of the system on the previous image. Two areas with a BT below $233 \mathrm{~K}$ and larger than $3500 \mathrm{~km}^{2}$ detected on two successive images (with maximum $2 \mathrm{~h}$ time difference) are considered as a same system if they overlap each other over at least $5 \%$. If for several clouds these conditions are verified, the cloud presenting the smallest area difference, difference in position and non-overlapping area will be considered as the evolution of the system identified on the previous image (Figure 1). These steps are repeated until the image does not contain any more contiguous area of pixels with BT below $233 \mathrm{~K}$ of least $3500 \mathrm{~km}^{2}$. If this is the case, the tracking algorithm checks for the next following image with 1 -h interval and repeats the steps described above. A system presenting a contiguous area of BT below $233 \mathrm{~K}$ smaller than $3500 \mathrm{~km}^{2}$ cannot be considered as a forerunner any more and hence dissipates.

While a small area cut-off defines initiation and dissipation time, a large area criterion ensures that MCSs only are tracked. Hence, after tracking (the algorithm went through all images in the data set), all systems presenting an area larger than $30000 \mathrm{~km}^{2}$ for more than three consecutive hours at least once during their life cycle are selected. This definition is close to the definition of MCSs given by Laurent et al. (1998) who claimed that the systems showing a BT equal or below $213 \mathrm{~K}$ and an area larger than $30000 \mathrm{~km}^{2}$ for at least $6 \mathrm{~h}$, account for the main part of the total cloud coverage over the Sahelian region. A visual inspection of the systems tracked during the first week of August 2006 also shows that the cloud parameters of systems spending a large fraction of their LD at the border of the study area are not representative (e.g. the area is underestimated when the system is partially located outside the region of interest). Therefore, systems touching the border of our study area during more than two third of their lifetime (criteria 


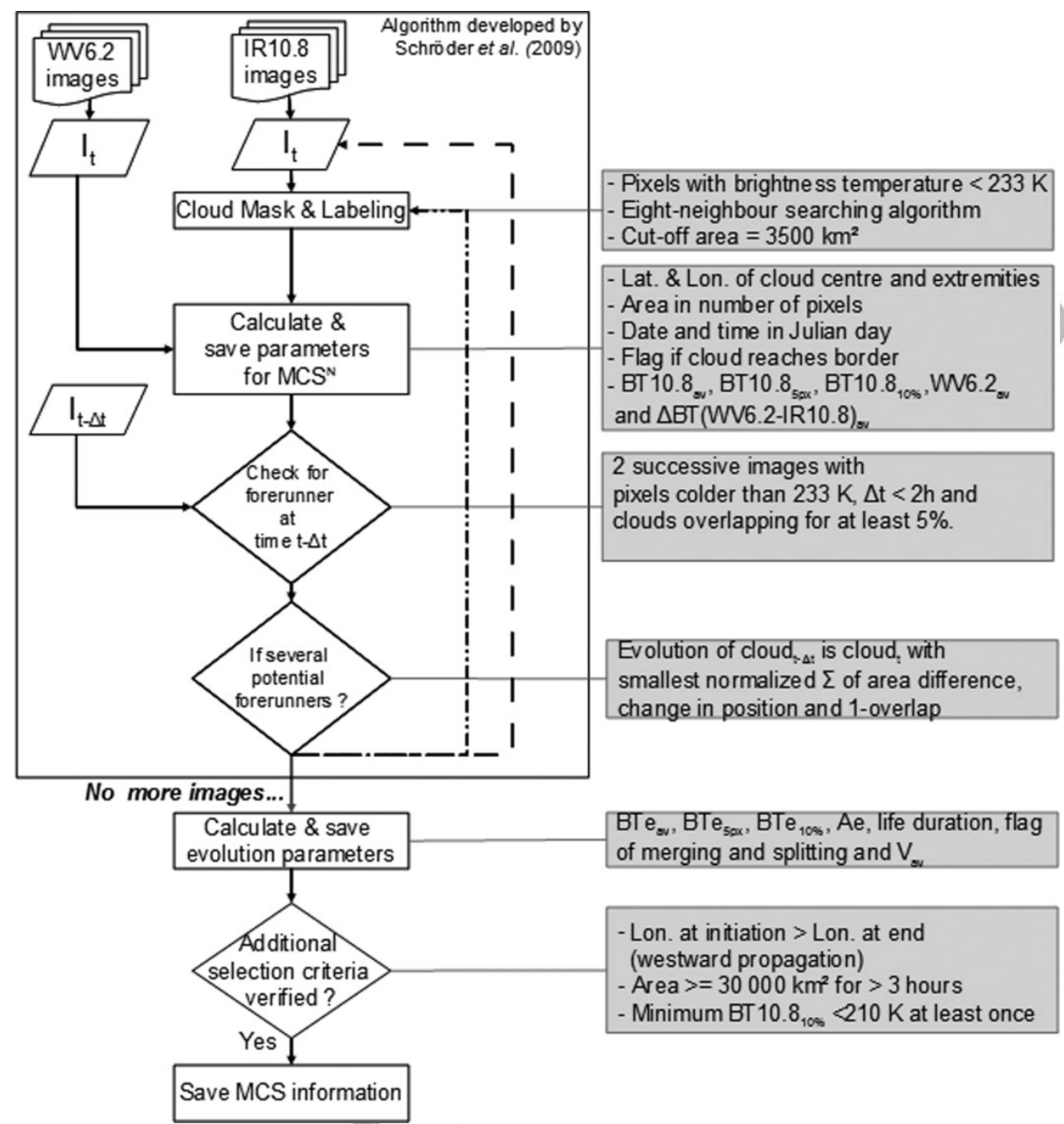

Figure 1. Conceptual• model of the tracking algorithm (initially developed by Schroeder et al., 2009). Data (parallelogram), processes (white boxes) and decisions (diamonds) are represented. First, all the potential clouds ( $N$ times $\left.\mathrm{MCS}_{N}\right)$ are selected and labelled on the image $I_{t}$. Second, for each $\mathrm{MCS}_{\mathrm{N}}$ the cloud parameters are estimated and saved. Next, the algorithm verifies if a forerunner of MCSN exist on the previous image $\mathrm{I}_{t-t}$ (with ${ }^{*} t$ less than $2 \mathrm{~h}$ ). Two clouds overlapping each other for at least $5 \%$ of their area on two consecutive images are considered as the same system. If several MCSs satisfy this condition, a set of criteria based on the area and position of the two potentially similar systems defines which cloud is considered as the forerunner. If there are still clouds present in the selected image $\mathrm{I}_{t}$ the loop follows the dash-dotted arrow. The dashed arrow indicates the loop when there are no more clouds in the image $\mathrm{I}_{t}$. In this case, the image $\mathrm{I}_{t}$ becomes $\mathrm{I}_{t-{ }^{*} t}$ and the image $\mathrm{I}_{t+}{ }_{t}$ becomes $\mathrm{I}_{t-}{ }^{*}$. After the loop has been gone through all images in the data set, the algorithm calculates the evolution parameters.

Finally, only the MCSs satisfying the definition of MCS are selected.

1 based on a visual inspection of several systems) are not

2 considered. Finally, MCSs are also defined as systems 3 showing at least once during their life cycle an embedded 4 cold convective core with an average BT colder than $5210 \mathrm{~K}$ ensuring that only deep convective systems are 6 tracked. Those cold convective cores correspond indeed 7 to strong convective activity, considered as triggers of 8 intense precipitation and are defined as the $10 \%$ coldest 9 pixels of the system. Delineating the cold convective core as the $10 \%$ coldest pixels is based on observations of Laurent et al. (2002). Indeed, the authors detected that MCSs identified with a temperature threshold of $233 \mathrm{~K}$ show convective cores representing approximately $10 \%$ of the total cloud area with BT below $210 \mathrm{~K}$, independently of their lifetime or size.
Next, after tracking, the average propagation speed $\left(V_{\mathrm{av}}\right)$, the cloud area at maximum extent $\left(A_{\max }\right)$, the $\mathrm{LD}$, the minimum in BT when averaged over the very cold convective core $\left(\mathrm{BT}_{\min }\right)$, the time during which the system shows a very cold convective core $\left(\mathrm{LD}_{\mathrm{cc}}\right)$, the local time at initiation, dissipation and $A_{\max }$ are estimated and saved. Table II resumes the different symbols and associated definitions and units used in this article.

To evaluate the very cold convective cores of the systems, over 30 systems are analysed visually whereby the very cold convective core is defined as the 5 coldest pixels of the system. $\mathrm{LD}_{\mathrm{cc}}$ corresponds to the life time of the system during which the average BT of the 5 coldest pixels is below $200 \mathrm{~K}$. Defining the cold convective core as the 5 coldest pixels rather than the $10 \%$ coldest pixels 
Table II. Used symbols and associated definitions and units for cloud and rain variables.

\begin{tabular}{|c|c|}
\hline Symbols & Definitions and units \\
\hline$A_{\max }$ & Maximum area $\left(\mathrm{km}^{2}\right)$ \\
\hline$V_{\mathrm{av}}$ & Propagation speed $\left(\mathrm{m} \mathrm{s}^{-1}\right)$ \\
\hline LD & Life duration $(\mathrm{h})$ \\
\hline $\mathrm{LD}_{\mathrm{cc}}$ & Life duration of the cold convective core (estimated as the 5 coldest pixels) (h) \\
\hline $\mathrm{BT}_{\min }$ & Minimum BT of the cold convective core (averaged over the 5 coldest pixels) \\
\hline$p_{\max }$ & 3-hourly precipitation averaged over the 10 most rainy pixels $\left(\mathrm{mm} \mathrm{h}^{-1}\right)$ \\
\hline$p_{\text {av }}$ & 3-hourly precipitation averaged over entire cloud cover $\left(\mathrm{mm} \mathrm{h}^{-1}\right)$ \\
\hline$p_{\text {tot }}$ & 3-hourly precipitation summed over entire cloud cover $\left(\mathrm{mm} \mathrm{h}^{-1}\right)$ \\
\hline$p_{\max }$ & Maximum intense precipitation (over the entire life cycle) $\left(\mathrm{mm} \mathrm{h}^{-1}\right)$ \\
\hline$p_{\text {av }}$ & Mean precipitation (averaged over the entire life cycle) $\left(\mathrm{mm} \mathrm{h}^{-1}\right)$ \\
\hline$p_{\text {tot }}$ & Total precipitation (summed over the entire life cycle) $\left(\mathrm{mm} \mathrm{LD}^{-1}\right)$ \\
\hline
\end{tabular}

(a)

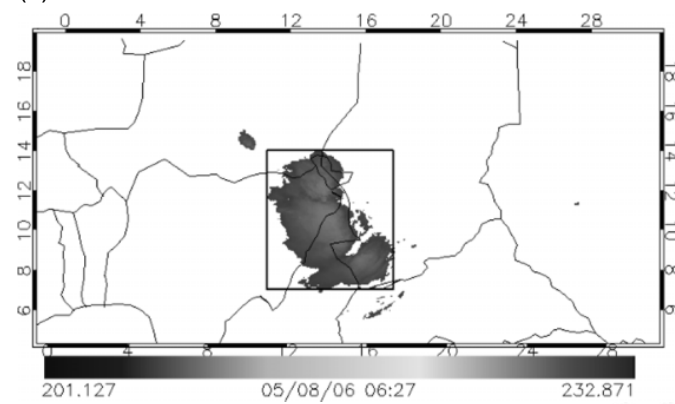

(b)

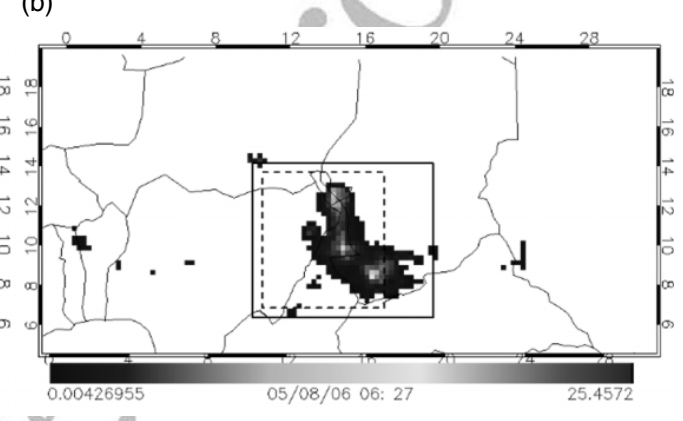

Figure 2. Overlay• method for retrieving the associated rain variables on the TRMM images. MCS identified on a Meteosat 10.8 IR image with BT below $233 \mathrm{~K}$ (left) and the corresponding rainfall amount (in $\mathrm{mm} \mathrm{h}^{-1}$ ) retrieved on a TRMM precipitation image (right). On the right figure dashed square corresponds to extreme latitudes and longitudes of the cloud, plain square corresponds to the same square including a buffer to retrieve rain variables. This figure is available in colour online at wileyonlinelibrary.com/journal/joc

(as suggested by Laurent et al., 2002) is more valuable since at some stages of the life cycle of the MCS the $10 \%$ coldest pixels correspond to a fraction of the cloud area larger than the convective core. This is especially true for the MCSs at mature stage when convective activity is concentrated over a small area, while the divergence at the cloud top is already important and the subsequent anvil cloud large.

Some authors reported the need to use images with small temporal sampling (here $15 \mathrm{~min}$ which corresponds to the temporal resolution of Meteosat) such that small and rapid systems are not missed (Schröder et al., 2009). However, the optimal temporal resolution (here defined as the best compromise between accuracy, computation time and data amount) is a function of the definition of MCSs (in particular on the overlap threshold, area cutoff and time-related criteria). We tested the sensitivity of the number of tracked MCSs on variations in temporal resolutions (15 $\mathrm{min}, 30 \mathrm{~min}$ and $1 \mathrm{~h}$ ). The largest cloud coverage was tracked with a temporal resolution of 30 min. As the main goal is on large MCSs only and the rain variables extracted from TRMM are only available at a 3-hourly temporal resolution, MCSs are tracked on Meteosat images at regular time intervals of $1 \mathrm{~h}$, reducing the amount of data by a factor of four.
The 3-hourly TRMM satellite images (3B42) provide rain rate estimates (averages over the time range $\pm 90 \mathrm{~min}$ ) at a $0.25^{\circ}$ spatial resolution based on the on-board precipitation radar, Microwave Imager instrument and Visible and Infrared Scanner (NASDA Earth Observation Centre, 2001). To assign the generated precipitation (estimated from the TRMM data) to each MCS (delineated on IR Meteosat images), boxes are drawn over the TRMM data corresponding to the extreme latitudes and longitudes of the systems as illustrated in Figure 2. On the basis of a visual inspection of the 30 systems mentioned previously, we observed that a better overlay between the precipitation data and the Meteosat images is obtained by applying a larger buffer to the box side corresponding to the trailing edge (approximately $200 \mathrm{~km}$ ) and a smaller buffer to the other sides (approximately $55 \mathrm{~km}$ ) (Figure 2). This indeed reduces the overlay errors emerging from the differences in spatial and temporal resolution between the TRMM and Meteosat images and from the approximation of the cloud area as a rectangular box. Nonetheless, it is still important to keep in mind the disparate time resolutions between the rain variables and cloud parameters ( $1 \mathrm{~h} \mathrm{vs} 3 \mathrm{~h}$ ) when studying the recurrent sequences of rain variables and cloud parameters. 
Every $3 \mathrm{~h}$ (when the hour of acquisition of the TRMM and Meteosat images coincides), for each identified system, average $\left(p_{\text {av }}\right)$, total $\left(p_{\text {tot }}\right)$ and intense $\left(p_{\max }\right)$ precipitation are calculated. The latter is defined as the average rain rate over 10 TRMM pixels showing the most intense rainfall. The cloud parameters maximum intense precipitation $\left(P_{\max }\right)$, average precipitation $\left(P_{\mathrm{av}}\right)$ and total precipitation $\left(P_{\text {tot }}\right)$ are then calculated as follow:

$$
\begin{aligned}
P_{\max } & =\max \left(p_{\max }\right) \\
P_{\mathrm{av}} & =\operatorname{mean}\left(p_{\mathrm{av}}\right) \\
P_{\mathrm{tot}} & =\Sigma\left(p_{\mathrm{tot}}\right)
\end{aligned}
$$

To differentiate the moderate rain events from the more intense rain events, a comparison is made between the occurrence and the behaviour of the systems presenting values of $P_{\max }$ below $5 \mathrm{~mm} \mathrm{~h}^{-1}$ and the systems presenting values of $P_{\max }$ above $10 \mathrm{~mm} \mathrm{~h}^{-1}$. These thresholds have been defined based on observations and results of Adler and Negri (1988) and Sui et al. (1997), who attempted to distinguish the stratiform component from the convective cloud. While discussing the results, it is important to keep in mind that $P_{\max }$ has been calculated as an average over a relatively large area (10 TRMM pixels $\sim 780 \mathrm{~km}^{2}$ ) and with a temporal resolution of $3 \mathrm{~h}$. This may explain the relatively low values of $P_{\max }$ encountered in this study compared to the literature (Schumacker and Houze, 2004; Schrage et al. 2006).

A quantitative measure of the strength of the relationships between cloud parameters and $P_{\max }$ and between $P_{\max }$ and the two other rain variables, $P_{\text {av }}$ and $P_{\text {tot }}$, is estimated using a Spearman's rank correlation coefficient. This was preferred over the more common Pearson's correlation coefficient as the latter is a parametric test assuming that both variables are normally distributed. The rank correlation is therefore less restrictive and is based on the probabilistic notion that a correlation exists between two variables if the probability that an increase/decrease in one variable will result in an increase/decrease in the other variable (McPherson, 1990). Hence a continuously increasing or decreasing trend line will be reflected by a high rank correlation coefficient but it does not assume a linear relationship between the variables.

While the rank correlation quantifies the degree and direction by which the cloud parameters vary pairwise with the generated precipitation, 2D regression models give an indication about the shape of the relation between the two variables and eventually allow to estimate the rain variables based on single cloud parameters. Because of the non-normality of some cloud parameters and rain variables the relationships between the parameters and variables cannot be expressed by simple linear models. Therefore, we use the power transformation method presented by Box and Cox (1964), which transforms the data as follow:

$$
X^{\prime}(\lambda)=\left(X^{\lambda}-1\right) / \lambda
$$

The purpose of the transformation is to raise the data to the power $\lambda$, which renders the data more or less normal (Sakia, 1992). In this study, $\lambda$ is selected among a vector of values between -3 and 3 and the most appropriate value is estimated using a maximum likelihood method. The relationship between the transformed cloud parameters and rain variables can then be modelled by means of linear models as it satisfies the assumptions for regression of linearity, normality and non-autocorrelation. In this research, we fit through the transformed data the following simple $2 \mathrm{D}$ equation:

$$
y^{\prime}=a+b x^{\prime}
$$

where $x^{\prime}$ is a transformed cloud parameter and $y^{\prime}$ the transformed rain variable. After, estimations of transformed data can be converted back to the appropriate distribution by inverting the Box-Cox transformation.

\section{Results and discussion}

3.1. Distribution of cloud parameters and maximum intense precipitation

A total of 358 MCSs are tracked between 1 July and 22 September 2006. The 358 systems account for approximately $70 \%$ of the precipitation fallen in the study area over the $84 \mathrm{~d}$. The distribution of $A_{\max }$ (Figure 3(a)) indicates that more than $90 \%$ of the MCSs show an $A_{\max }$ below $200000 \mathrm{~km}^{2}$. $A_{\max }$, showing a heavily skewed distribution, follows a log-normal distribution with an expected value around $56000 \mathrm{~km}^{2}$, which is almost twice as much as the large area criterion defined for the tracking. Similar to Arnaud et al. (1992), who studied MCSs with a temperature threshold of $233 \mathrm{~K}$ over West Africa from Lake Chad to the Atlantic, we observe some systems with maximum cloud areas above $400000 \mathrm{~km}^{2}$ (Figure 3(a)). The fastest MCS has a propagation speed equal to $21.3 \mathrm{~m} \mathrm{~s}^{-1}$, while on average the propagation speed, which follows a normal distribution, is $9.6 \mathrm{~m} \mathrm{~s}^{-1}$ and the standard deviation $3.6 \mathrm{~m} \mathrm{~s}^{-1}$ (Figure 3(b)). This is smaller than the average speed estimated by Chong et al. (1987) and Desbois et al. (1988), who observed that the westward mean speed of squall lines over West Africa lies between 12 and $19 \mathrm{~m} \mathrm{~s}^{-1}$. However, as noticed by Mathon and Laurent (2001), squall lines are considered the fastest systems among the MCSs. Therefore, a mean speed between 12 and $19 \mathrm{~m} \mathrm{~s}^{-1}$ is likely to be an overestimation for a more general classification of MCSs. Mathon and Laurent (2001) and Mathon et al. (2002) estimated a mean propagation speed for Sahelian MCSs consistent with our observations, notably between 8 and $12 \mathrm{~m} \mathrm{~s}^{-1}$ and between 10 and $15 \mathrm{~m} \mathrm{~s}^{-1}$, respectively. Following Laing et al. (2008) most convective clouds in Tropical North Africa have a propagation speed between 10 and $20 \mathrm{~m} \mathrm{~s}^{-1}$ and an overall propagation speed of $12 \mathrm{~m} \mathrm{~s}^{-1}$. The long-lived MCS lasts in our study for $58 \mathrm{~h}$. As for $A_{\max }, \mathrm{LD}$ follows a log-normal distribution with an expected value of $8.3 \mathrm{~h}$ (Figure 3(c)). This is 
(a)

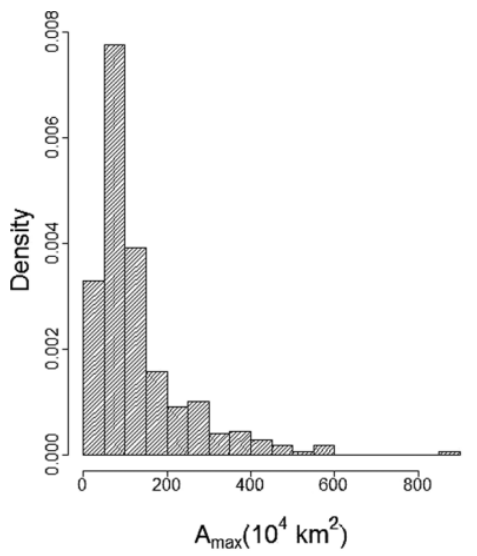

(d)

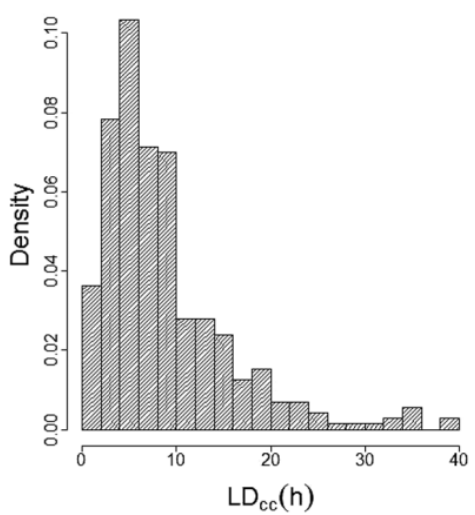

(b)

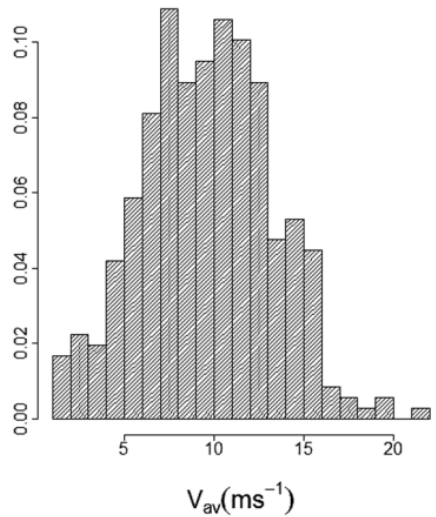

(e)

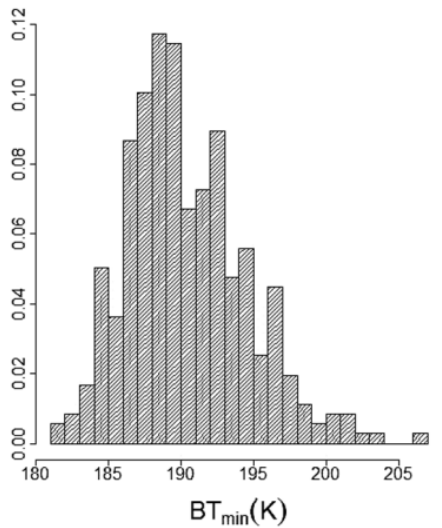

(c)

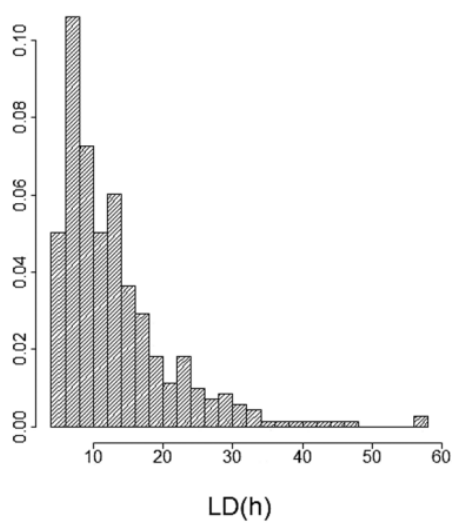

(f)

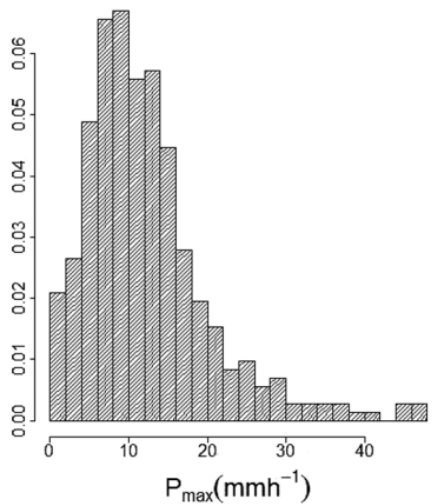

Figure 3. Distribution of the cloud parameters and rain variables: $A_{\max }, V_{\mathrm{av}}, \mathrm{LD}, \mathrm{LD}_{\mathrm{cc}}, \mathrm{BT}_{\min }$ and $P_{\max }$, recorded over the 3 summer months of 2006 .

slightly less than the average lifetime observed by Hodges and Thorncroft (1997), who noticed that over the Sahel MCSs are longer-lived and are usually lasting for more than a day. However, this difference might be explained by the use of disparate BT thresholds and temporal resolutions (Table I).

MCSs tracked during the 3 months generally exhibit deep convection during on average $6.35 \mathrm{~h}$ and have at least once in their lifetime a very cold convective core around $190 \mathrm{~K} . \mathrm{LD}_{\mathrm{cc}}$ follows a positive skewed Gumbel distribution (Figure 3(d)) and $\mathrm{BT}_{\min }$ a logistic distribution (Figure 3(e)). Unfortunately, as we could not encounter the two last cloud parameters in previous studies, results of $\mathrm{LD}_{\mathrm{CC}}$ and $\mathrm{BT}_{\min }$ cannot be compared. In the next section, the results show, however, that these two variables present sizeable information on MCSs.

$P_{\max }$ shows a Weibull distribution with an expected average value of $12.3 \mathrm{~mm} \mathrm{~h}^{-1}$ (Figure 3(f)). For comparison, Schumacher and Houze (2004) observed, based on TRMM precipitation images, that the mean conditional stratiform and convective rain rates over West Africa are 1.8 and $14 \mathrm{~mm} \mathrm{~h}^{-1}$, respectively. Accordingly, we can state that $P_{\max }$ values close or above the average $\left(12.3 \mathrm{~mm} \mathrm{~h}^{-1}\right)$ coincide with convective rain. The most intense system showed a value of $P_{\max }$ attaining $47 \mathrm{~mm} \mathrm{~h}^{-1}$. This is slightly less than the results of Schrage et al. (2006), who analysed convective systems in Central Benin. The authors reported indeed peaks in precipitation between 50 and $70 \mathrm{~mm} \mathrm{~h}^{-1}$ from groundbased measurements during the overpass of two squall lines. The small values for $P_{\max }$, when compared with both the results from Schumacher and Houze (2004) and Schrage et al. (2006), may be associated to the broad spatial and temporal resolution of the TRMM data set $\left(\sim 780 \mathrm{~km}^{2}\right.$ and $\left.3 \mathrm{~h}\right)$ as well as to the differences in definition of $P_{\max }$.

3.2. Diurnal cycle and recurrent sequences of cloud parameters and rain variables during the life time of the system

Neither the cloud characteristics nor the time-related variables (e.g. initiation or dissipation) of the 358 tracked systems show a clear temporal evolution between July and September 2006 (not shown). In contrast, the diurnal cycles of the cloud parameters and initiation and dissipation time are more apparent. Most of the MCSs initiate in the afternoon around 15:00 LT after being triggered by a buoyant atmospheric layer at the surface resulting 
(a)

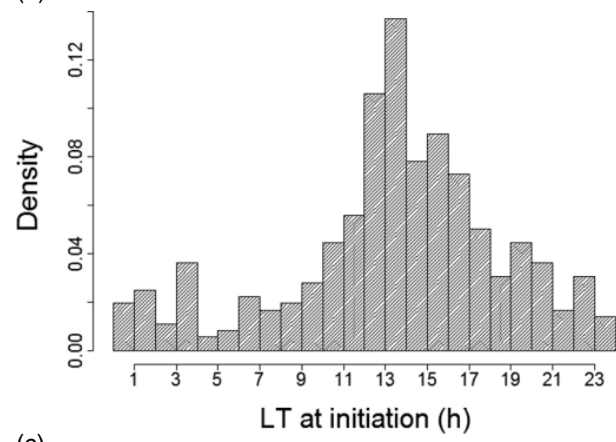

(c)

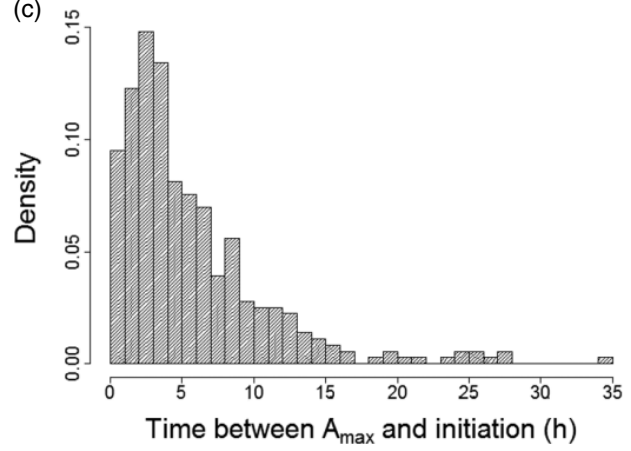

(b)

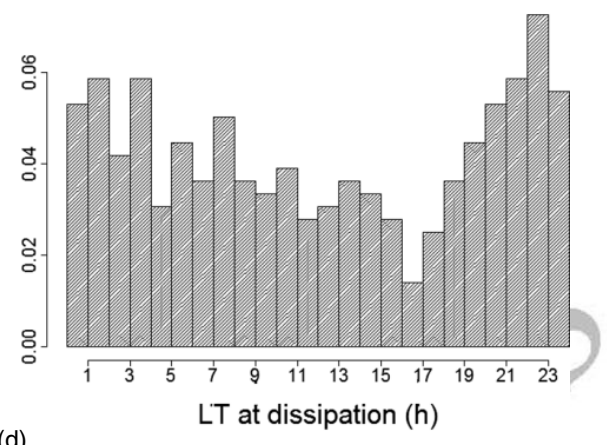

(d)

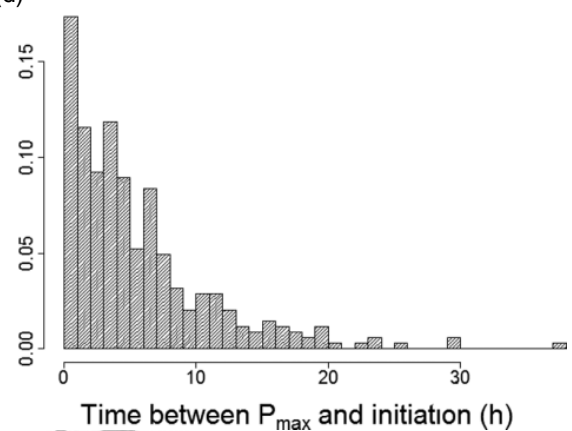

Figure 4. Distribution of initiation and dissipation of MCS according to the local time and time lapse between $A_{\max }$ and initiation and $P_{\max }$ and initiation.

1 from a strong solar radiation around noon (Figure 4(a)).

2 This peak in initiation is also in agreement with the results from previous studies (Desbois et al., 1988; Laing and Fritsch, 1993; Mathon and Laurent, 2001; Mohr, 2004; Schröder et al., 2009). The time at dissipation is more variable, although peaks in dissipation are observed mainly later during the night around 23:00 LT. Peaks in dissipation 1 or $2 \mathrm{~h}$ before local noon, as observed by Laing et al. (2008), are not evident with our data (Figure 4(b)). As suggested by Figure 4(c) and (d), for $60 \%$ of the tracked MCSs the time lapse between initiation and maximum cloud cover and the time lapse between initiation and $P_{\max }$ are between 0 and $5 \mathrm{~h}$, with an average of 3 and $2 \mathrm{~h}$, respectively. According to previous studies, strong convective activity is usually associated with intense precipitation resulting from a rapid vertical updraft and is followed by an expanding anvil cloud (Desbois et al., 1988; Hodges and Thorncroft, 1996; Nuret and Chong, 1998; Mathon and Laurent, 2001; Schröder et al., 2009). In other words, a peak in precipitation should be preceded by a minimum in BT in the cold convective core (corresponds to a strong vertical updraft) and followed by a maximum in cloud coverage. This is confirmed by the Figure 4(c) and (d) as well as Figure 5(a). The latter shows the probability of occurrence of the three variables as a function of the normalized life cycle. Life time values for each system have been brought to a common scale from 0 to 100 to allow direct comparison of the recurrent sequences of cloud parameters over different time lengths.
As noticed previously, most of the MCSs initiate in the afternoon following solar radiation at noon and for more than half of the tracked MCSs the time lapse between initiation and $P_{\max }$ varies around $2 \mathrm{~h}$ (Figure 4(d)). Hence, it is not surprising to observe a peak in precipitation later in the afternoon and evening between 15:00 and 21:00 LT as shown in Figure 5(b). Another peak in $P_{\max }$ is also observed between 02:00 and 05:00 LT (corresponds to the peak at 03:30 LT knowing that the time resolution of the TRMM images is $\pm 90 \mathrm{~min})$. Indeed, in the coastal regions convective activity may continue at night and being triggered early in the morning due to the strengthening of the lowlevel West monsoon flow occurring over West Africa and pumping warm moist air into the boundary layer (Desbois et al., 1988; Futyan and Del Genio, 2007; Schröder et al., 2009). The small coastal area of Togo, Benin and Nigeria included in the study area thus influences the diurnal cycle of $P_{\max }$. When considering only the MCSs presenting $P_{\max }$ at 03:30 LT and later at 06:30 LT, we indeed observe that at $P_{\max }$ the systems are tracked at lower latitudes between 0 and $4{ }^{\circ} \mathrm{N}$, which corresponds to the coastal areas (not shown).

The histogram in Figure 5(b) allows to compare the occurrence and diurnal cycle of low to moderate precipitation events $\left(P_{\max }<5 \mathrm{~mm} \mathrm{~h}^{-1}\right)$ against more intense precipitation events $\left(P_{\max }>10 \mathrm{~mm} \mathrm{~h}^{-1}\right)$. Of the 358 tracked systems, 49 systems generate only low to moderate precipitation events, while 194 systems generate intense precipitation. The peaks in $P_{\max }$ observed in the late afternoon and early night mainly 
(a)

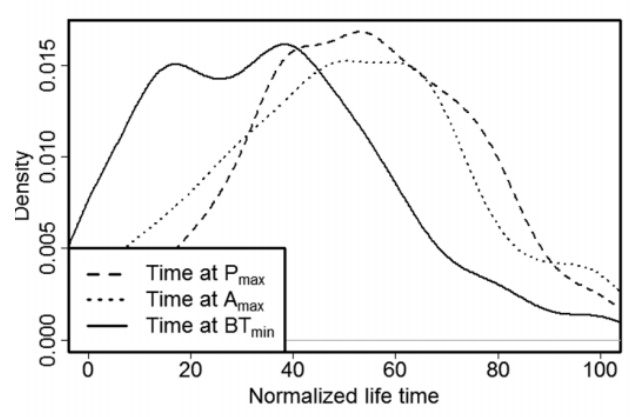

(c)

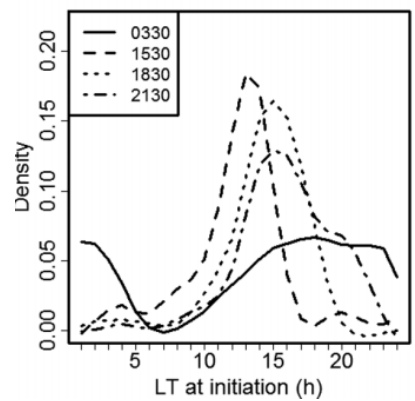

(d)

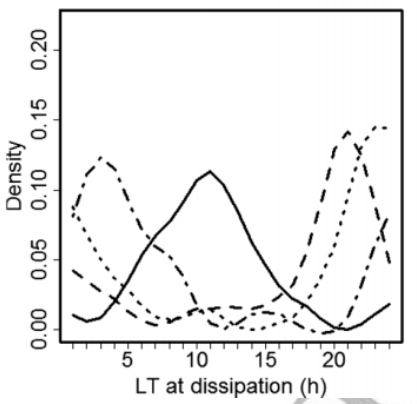

(b)

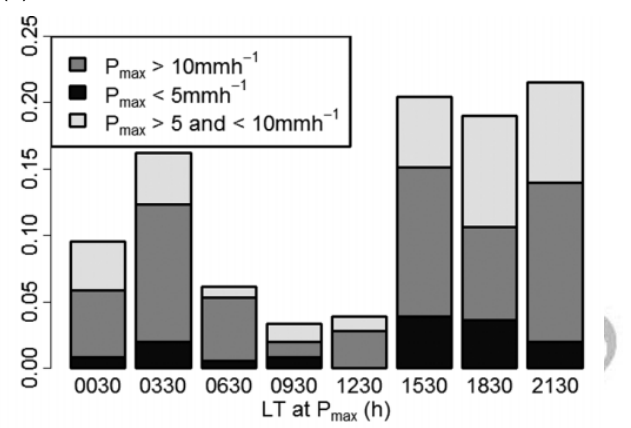

(e)

Figure 5. Density plot of the time at $P_{\max }, A_{\max }$ and $\mathrm{BT}_{\min }$ according to the normalized life time of the systems (a), histogram of the time at $P_{\max }$ according to the local time (b) and density estimate of the local time at initiation (c), dissipation (d) and $A_{\max }$ (e) for MCSs showing a peak in $P_{\max }$ at 03:30 LT (plain line), 15:30 LT (dashed line), 18:30 LT (dotted line) and 21:30 LT (dashed-dot line), respectively.

results from strong convective rain events. Mohr (2004) observed over West Africa a transition in the diurnal cycle of the total precipitation from a bimodal cycle over the semi-desert north of $15^{\circ} \mathrm{N}$ to a rather unimodal diurnal cycle over the forest area south of $10^{\circ} \mathrm{N}$. Figure $5(\mathrm{~b})$ shows that in our study area, where land cover is dominated by savanna and semi-desert, low to moderate and more intense precipitation events rather follow a bimodal diurnal cycle with peaks during the night around $03: 00$ LT and in the afternoon at 15:00 and 18:00 LT. Mohr (2004) also mention that total precipitation in the early morning between 02:00 and 06:00 LT mainly results from stratiform and decaying rain systems. However, if we consider that low to moderate rain events are stratiform and decaying systems, our data does not confirm this statement. Indeed, in the early morning the proportion of more intense rain events remains higher (Figure 5(b)).

To evaluate if systems show different diurnal cycles and recurrent sequences as a function of the time they are generating maximum intense precipitations, the concurrence between initiation, dissipation, $A_{\max }$ and $P_{\max }$ is analysed once more after a classification of the systems based on the peaks in Figure 5(b). Systems showing maximum convective activity in the late afternoon or early evening, around 15:30 and 18:30 LT, mostly initiate $2 \mathrm{~h}$ earlier (Figure 5(c)). This is in agreement with the observations made for Figure 4(d). In contrast, systems showing maximum intense precipitation around $21: 30$ LT show a more variable diurnal cycle in initiation with most of the systems initiating between 15:00 and 20:00 LT. The preferential time for initiation is even more variable for systems showing $P_{\max }$ around $03: 30$ LT generally extending from 15:00 to $03: 00$ LT. Overall, Figure 5(c) shows that the lapse of time between initiation and $P_{\max }$ increases when the systems initiate later in the evening and at night. This confirms that convective activity tends to build-up more rapidly in the afternoon than in the evening and at night. According to Figure 5(d) MCSs generally dissipate 4 and $6 \mathrm{~h}$ after they have showed a maximum in intense precipitation. As observed in Figure 5(e), whatever the class of systems, $P_{\max }$ generally precedes $A_{\max }$ with $2 \mathrm{~h}$. Accordingly, in contrast to the build-up of convective activity the time needed for the system to decay does not seem to be affected by the local time.

Of the 358 tracked systems, 195 systems neither split nor merge, or reach the border of the study area at the time of $P_{\max }$. When considering the 195 systems only, very similar distributions (not shown) and results were obtained. Consequently, although split and merger events are considered as disruptive elements (Schröder et al., 2009), they do not significantly alter the results of this study.

Above results appear to be consistent with what is observed in the literature. However, it is not uncommon that cloud parameters and time-related variables have disparate definitions. For instance, we defined $\mathrm{BT}_{\min }$ over a constant area (5 coldest Meteosat pixels), while Schröder et al. (2009) defined it over the lowest $2 \%$ of the total cloud area. Hence at the end of the mature stage when the system reaches its maximum cloud area, the $\mathrm{BT}_{\text {min }}$ like estimated by Schröder et al. (2009) will be 
1 larger than the one estimated in this study. Similarly, 2 Schröder et al. (2009) only consider MCSs which did 3 not exhibit neither a merger nor a split event resulting 4 in statistics dominated by generally smaller systems. 5 Inconsistencies in cloud parameter definitions as well as in the definition of MCS, make it a hard task to compare 7 results with previous studies, claiming the need of an 8 universal definition of MCSs.

\subsection{Relationships between cloud parameters and $P_{\max }$}

Table III shows the rank correlation coefficients between the cloud parameters and the three rain variables, $P_{\max }$, $P_{\text {tot }}$ and $P_{\mathrm{av}}$. The coefficients are, for most variables, significant at $99 \% . P_{\max }$ and $P_{\text {tot }}$ are better correlated to the cloud parameters than $P_{\mathrm{av}}$. Both rain variables are also significantly and positively correlated with each other. $P_{\mathrm{av}}$ does not appear to be as good correlated with neither $P_{\text {tot }}$ nor $P_{\max }$, suggesting that an in-depth understanding of the rainfall variability as a function of the cloud parameters should focus on the rainfall peaks or the total precipitation rather than on the average precipitation. $V_{\text {av }}$ appears to be slightly less correlated with both $P_{\max }$ and $P_{\text {tot }}$ explaining our choice to focus on the four other variables. The positive rank correlations between $P_{\text {tot }}$ and the cloud parameters $A_{\max }, \mathrm{LD}$ and $\mathrm{LD}_{\mathrm{cc}}$ and the negative rank correlation between $P_{\text {tot }}$ and $\mathrm{BT}_{\text {min }}$ confirm the fact that larger, deeper and longerlived systems are more likely to generate more rain than weaker, short-lived and smaller systems. This has also been observed by Laurent et al. (1998) and Mathon et al. (2002). However, following the estimated rank correlations, there is a stronger relationship between $P_{\max }$ and $\mathrm{LD}_{\mathrm{cc}}$ than between $P_{\max }$ and LD. Accordingly, we can add to the statement of Laurent et al. (1998) and Mathon et al. (2002) that long-lived cold convective cores $\left(\mathrm{LD}_{\mathrm{cc}}\right)$ showing at least once during their life cycle very cold cloud top temperatures $\left(\mathrm{BT}_{\min }\right)$ are more likely to exhibit more intense precipitation over the Sahelian band. $\mathrm{LD}_{\mathrm{cc}}$ as defined in this study have not been used yet in previous research to characterize MCSs. However, this variable presents a significant advantage as it is not as sensitive to the used methodology compared to LD and in particular to the cut-off area and BT threshold used for the tracking of MCSs. We therefore recommend to further investigate this variable in future studies.

In a concern to improve the relationships between cloud parameters and rain variables, the rank correlation coefficients are recalculated considering the most intense

Table III. Rank correlation coefficients between rain variables and cloud parameters.

\begin{tabular}{lllrrrrr}
\hline$A_{\max }$ & $V_{\mathrm{av}}$ & $\mathrm{LD}$ & $\mathrm{BT}_{\min }$ & $\mathrm{LD}_{\mathrm{cc}}$ & $P_{\max }$ & $P_{\mathrm{av}}$ & $P_{\text {tot }}$ \\
\hline$P_{\max }$ & $0.46^{\mathrm{a}}$ & $0.28^{\mathrm{a}}$ & $0.49^{\mathrm{a}}$ & $-0.44^{\mathrm{a}}$ & $0.51^{\mathrm{a}}$ & 1 & \\
0.02 & $0.26^{\mathrm{a}}$ & 0.08 & $-0.24^{\mathrm{a}}$ & $0.20^{\mathrm{a}}$ & $0.67^{\mathrm{a}}$ & 1 & \\
$0.68^{\mathrm{a}}$ & $0.33^{\mathrm{a}}$ & $0.71^{\mathrm{a}}$ & $-0.48^{\mathrm{a}}$ & $0.66^{\mathrm{a}}$ & $0.83^{\mathrm{a}}$ & $0.44^{\mathrm{a}}$ & 1 \\
\hline
\end{tabular}

${ }^{a}$ Coefficients at a significant level of $99 \%$. rain events $\left(P_{\max }>10 \mathrm{~mm} \mathrm{~h}^{-1}\right)$ and the largest MCSs (systems showing an area larger than $80000 \mathrm{~km}^{2}$ for more than $3 \mathrm{~h}$ ) separately. However, none of these two cases present better rank correlation coefficients. Excluding the systems which either merge or split or reach the border at the time of maximum intense precipitation does not result in better correlation coefficients neither (not shown).

Expect for $\mathrm{BT}_{\min }$, the data for $A_{\max }, \mathrm{LD}, \mathrm{LD}_{\mathrm{cc}}$ and $P_{\text {max }}$ are transformed using the Box-Cox method solving the problems of non-normality. The smallest error sum of squares are obtained with values of $\lambda$ equal to -0.6 , $-0.7,0.3$ and 0.3 , respectively. As shown in Figure 6, the Box-Cox transformation does not result in large coefficients of determination $\left(R^{2}\right)$. However, although the homoscedasticity is slightly reduced, the assumptions of nonlinearity, non-autocorrelation and normality are verified after transformation. Regression lines are plotted together with the density scatter-plots in Figure 6 and the intercepts, slopes and associated standard deviations are given in Table IV. The regression coefficients are significant at $99 \%$ for the four models (Table IV) and, as suggested by the positive $R^{2}$, using the regression models rather than the average value will lead to a better estimation of $P_{\max }$.

On the basis of the regression equations shown in Figure 6 and by inverting the Box-Cox transformation, the cloud parameters can be used as proxy variable to have a first estimation of $P_{\max }$. In Figure 7, simulations of the transformed $P_{\max }$ are converted back to the appropriate distribution and plotted against the cloud parameters. Figure 7(a) and (b) concord with previous statements assuming that an increase in $A_{\max }$ and LD is generally associated with an increase in $P_{\max }$. However, the regression models show that once the LD and/or maximum cloud area exceeds approximately $13 \mathrm{~h}$ and $270000 \mathrm{~km}^{2}$ respectively, the slope of the regression equations approaches zero. Accordingly, variations in LDs and maximum cloud area above these thresholds do not significantly affect the generated maximum intense precipitation any more. Like previously shown with the rank correlation coefficients, Figure 7(b) and (c) confirm that an increase in the LD of the cold convective core and a decrease in minimum BT of the cold convective core also generate an increase in maximum intense precipitation. On the basis of Figure 7(b), we can add to the previous statement that variations in $\mathrm{LD}_{\mathrm{cc}}$ have a larger influence on $P_{\max }$ compared with variations in LD.

The rank correlation coefficients and nonlinear regression models confirm that maximum intense precipitation varies more or less with variations in $\mathrm{LD}$, maximum cloud coverage, LD of the cold convective core and minimum in BT in the cold convective core. However, the relationships between cloud parameters and rain variables are not as strong as expected. Indeed, the rank correlation coefficients remain relatively low and the density scatter-plots in Figure 6 indicate a significant deviation of the data from the model. Accordingly, a nonnegligible number of systems is located outside the band 

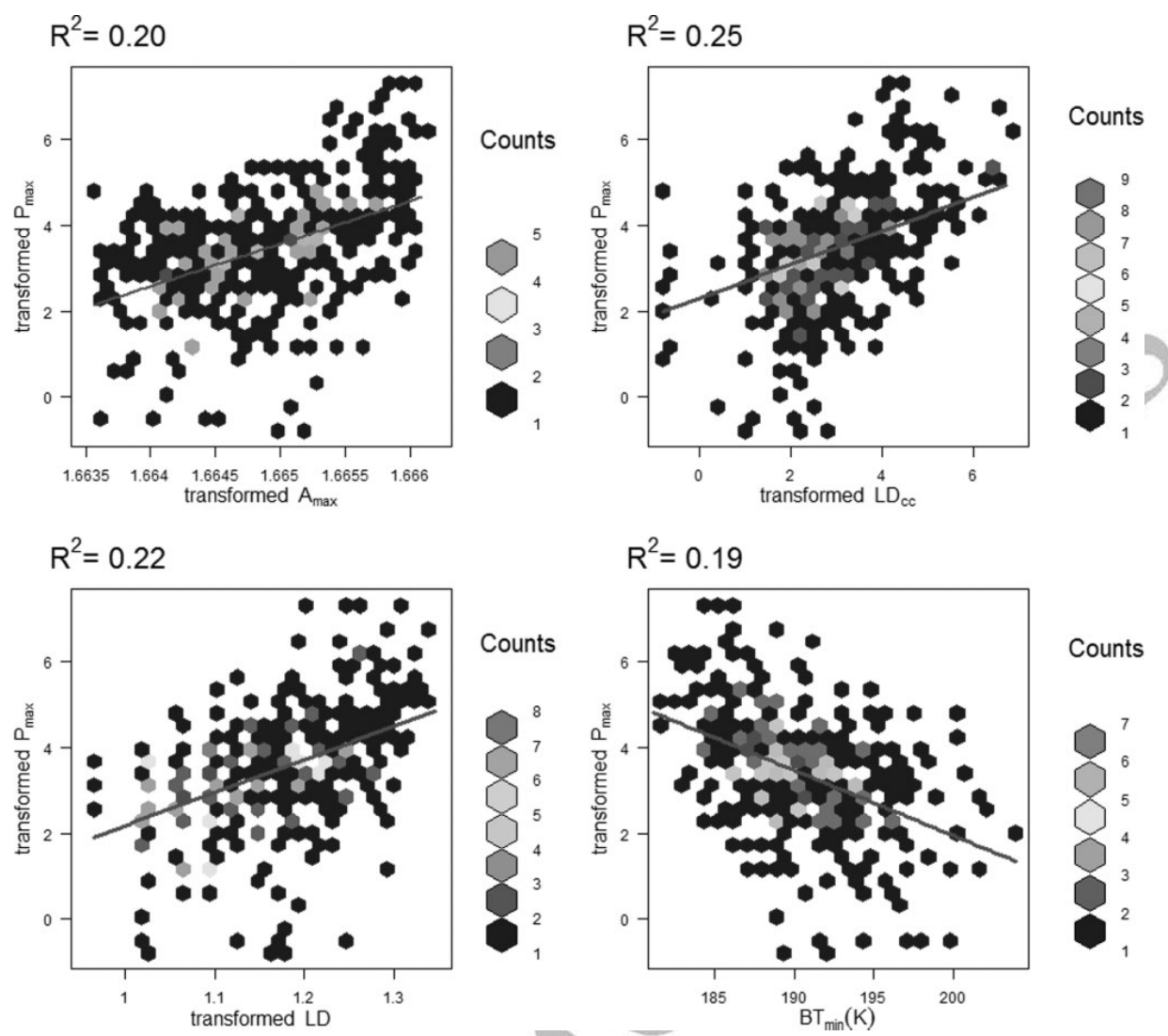

Figure 6. Density scatter-plots and nonlinear regression models (plain red line) between the transformed $P_{\max }$ versus the transformed cloud parameters and initial $\mathrm{BT}_{\min }$. The nonlinear regression models are of the form $y^{\prime}=a+b x^{\prime}$ where $y^{\prime}$ and $x^{\prime}$, aside from $\mathrm{BT}_{\min }$, have been transformed previously. The coefficient of determination, $R^{2}$, gives an indication of how well the model fits to the data. This figure is available in colour online at wileyonlinelibrary.com/journal/joc

Table IV. Regression coefficients and associated standard deviations, in parentheses, of the 2D nonlinear regression models between cloud parameters and rain •variables.

\begin{tabular}{lcccr}
\hline & $A_{\max }$ & $\mathrm{LD}_{\mathrm{cc}}$ & $\mathrm{LD}$ & $\mathrm{BT}_{\min }$ \\
\hline Intercept & $-1654.47^{\mathrm{a}}(172.04)$ & $1.88^{\mathrm{a}}(0.15)$ & $-5.52^{\mathrm{a}}(0.90)$ & $32.33^{\mathrm{a}}(3.28)$ \\
Slope & $990.41^{\mathrm{a}}(103.33)$ & $0.53^{\mathrm{a}}(0.05)$ & $7.70^{\mathrm{a}}(0.77)$ & $-0.15^{\mathrm{a}}(0.02)$ \\
\hline
\end{tabular}

${ }^{a}$ Regression coefficients at a level of $99 \%$.

of data and shows a different behaviour. A visual inspection of the evolution of the cloud parameters and rain variables of some of these systems allows us to define these as MCSs with intermittent periods of deep convection and/or showing large merger and split events. This is illustrated in Figure 8 showing how $A_{\max }$ and $P_{\max }$ vary over the life time of a system located once outside the band of data (Figure 8(a)) and once inside the band of data (Figure 7(b)). Regenerating cold pools, mesoscale vortices or trapped gravity waves are examples of events leading to intermittent periods of deep convection and/or large merger and split events (Laing et al., 2008). According to Futyan and Del Genio (2007), 15\% of the systems tracked during the rain season of 2005 over the Atlantic and African regions show a more complex evolution with multiple maxima in radius and minimum
BT. In this study, about half of the systems analysed and located outside the band of data in Figure 6(a) (9 of 15 systems) shows relatively large or small values of $A_{\max }$ and long LDs with numerous merger and split events. In comparison to $\mathrm{LD}_{\mathrm{cc}}$ and $\mathrm{BT}_{\min }, A_{\max }$ and $\mathrm{LD}$ are indeed more sensitive to disruptive events such as split and merger events.

\section{Conclusion}

The vulnerability of the Sahel with respect to rainfall and the great contribution of MCSs in the Sahelian rainfall budget explain the importance of an in-depth understanding of these systems. This study proposes a way to improve this understanding by (1) investigating the 
(a)

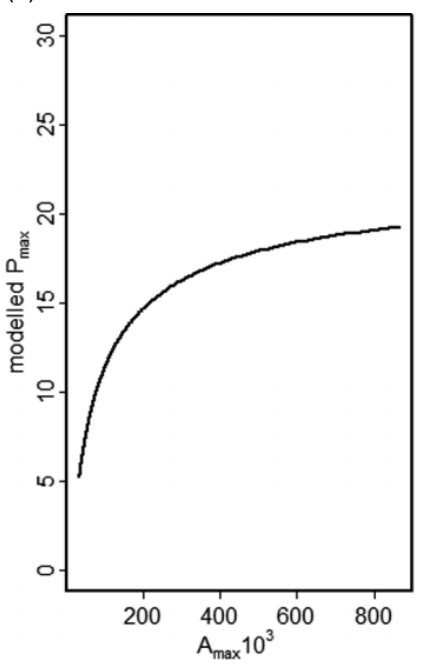

(b)

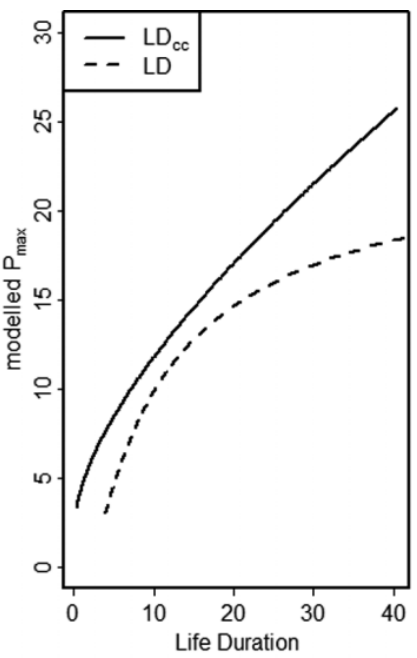

(c)

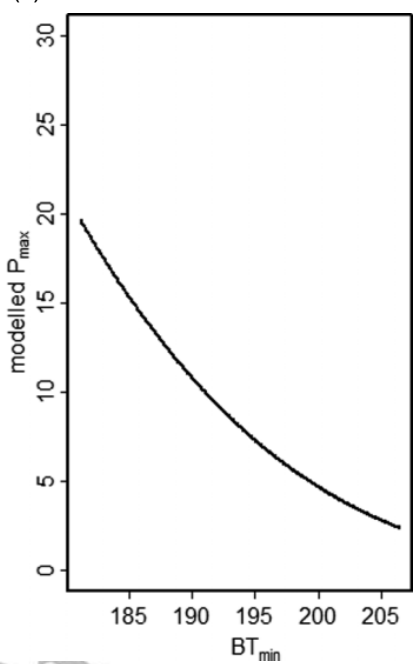

Figure 7. Nonlinear regression models between $P_{\max }$ and cloud parameters $\left(A_{\max }, \mathrm{LD}, \mathrm{LD}_{\mathrm{cc}}, \mathrm{BT}_{\min }\right)$, Simulations of transformed $P_{\max }$ have been converted back to the appropriate distribution and plotted against the cloud parameters.

(a)

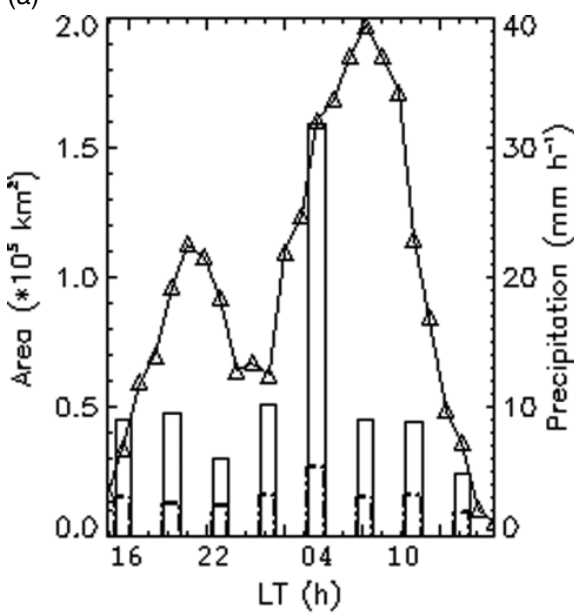

(b)

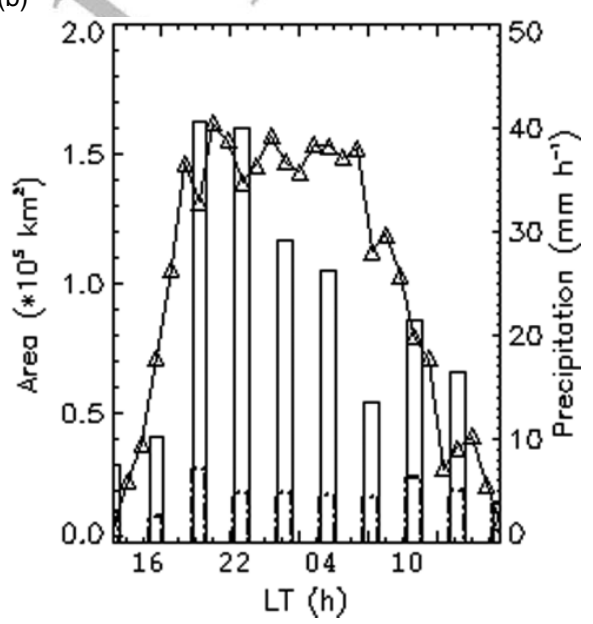

Figure 8. Example of MCSs with intermittent periods of deep convection (a) and with continuous convection (b). Plain bars correspond to the 3-hourly $p_{\max }$ (average precipitation of the 10 most intense rainy pixels in the system), dashed-dot bars to the 3-hourly $p_{\text {av }}$ (average precipitation over the entire cloud). The triangles connected by a continuous line correspond to the hourly $A_{\max }$ retrieved from Meteosat IR10.8 images. The maximum intense precipitation $P_{\max }$ is the maximum value of $p_{\max }$ over the life time of the system. $P_{\max }$ occurs around $03: 30$ LT and is equal

to $32 \mathrm{~mm} \mathrm{~h}^{-1}$ for the system in figure (a) and for the system in figure (b) $P_{\max }$ occurs around 18:30 LT and is equal to $41 \mathrm{~mm} \mathrm{~h}^{-1}$.

distributions and statistics of the cloud parameters and associated rain variables of MCSs, (2) looking into the diurnal cycles and recurrent sequences of these parameters and variables and (3) establishing relationships between them. This is done using two large-scale spatial resolution data sets: IR10.8 Meteosat images and TRMM precipitation data. MCSs are delineated and tracked on the successive IR Meteosat images and an overlay method is used to extract the associated precipitation data from the TRMM images. The study focuses on the Lake Chad region and the period of interest lasts from July till September 2006.

There are 358 MCSs retained by the tracking algorithm. These systems show realistic average maximum cloud areas, LDs and radiative properties when compared to results of previous studies. Systems generally present an average LD of $8.3 \mathrm{~h}$ and an average maximum cloud cover attaining $56000 \mathrm{~km}^{2}$ and generate a maximum intense precipitation of about $12.3 \mathrm{~mm} \mathrm{~h}^{-1}$. The average time during which MCSs show strong convective activity, is $6.35 \mathrm{~h}$ and the minimum BT over the cold convective core generally reached by a system is $190 \mathrm{~K}$.

Most MCSs initiate in the afternoon and show $3 \mathrm{~h}$ later a maximum in intense precipitation. The time at dissipation appears more variable than the initiation time, however, a peak in dissipation time is still observed later in the evening around 23:00 LT. Some systems also show a maximum in intense precipitation very early 
in the morning, which is explained by a strengthening of the South-West low-level monsoon flow at night time. The data does not only demonstrate that a clear daily cycle in initiation and dissipation of MCSs exists but also shows recurrent sequences of cloud parameters and rain variables over the life time of the systems. Indeed, whatever the time of initiation, dissipation or maximum intense precipitation, a rapid vertical updraft, approximated by a minimum in BT in the cold convective core, is generally followed by a maximum in intense precipitation and later by a maximum in cloud coverage resulting from an abrupt expansion of the anvil cloud.

The statistics and distributions of the cloud parameters and rain variables as well as the observed daily cycle and recurrent sequences of cloud parameters and rainfall variables confirm the validity of the data set and the usefulness of geostationary satellites for the study of everchanging large-scale weather events. Subsequently, the data can be used to establish relationships between cloud parameters and rain variables and this with the aim of using more easily estimated cloud parameters as proxy variables for the estimation of total and maximum intense rainfall of MCSs.

The Box-Cox transformation is used to solve the non-normality problems of the data for the maximum cloud coverage, LD and LD of the cold convective core as well as the maximum intense precipitation. The transformation method allows to develop a simple 2D nonlinear regression model between cloud parameters and maximum intense precipitation. The nonlinear regression and rank correlation coefficients support the findings of Laurent et al. (1998) and Mathon et al. (2002) that longlived, deeper and fast-moving MCSs are more likely to exhibit intense precipitation. We added to this knowledge that the longer the time during which the system shows strong convective activity (approximated by low BT in the cold convective core) and the lower the minimum BT in the cold convective core, the more likely the system will induce very strong intense precipitation. Our results also suggest that the life time during which MCSs show strong convective activity is better related to the maximum intense precipitation than the life time of the system. Moreover, the life time during which MCSs show strong convective activity is less sensitive to the tracking and threshold method. We therefore recommend to further explore this parameter in future studies.

Beyond the main objectives of this research, results also aid movement towards a classification scheme of MCSs based on their structural and radiative characteristics and rain variables. In this respect, geostationary satellite-based cloud parameters and rain variables have shown to be sufficiently robust. A classification scheme of MCSs is particularly relevant, among others, for the identification of MCSs and for representing distinct MCSs in climate models. Moreover, and as demonstrated in this study, the lack of an universal and objective classification scheme of MCSs often restrain the possibilities to compare results from studies conducted in the past and/or over different regions of interest. Beside a univer- 60 sal classification scheme of MCSs, further research may 61 also want to develop a metric integrating the structural 62 and radiative cloud characteristics over the entire lifetime 63 of the systems. Such metrics will be especially useful to 64 quantify the intensity of each MCS and could be relevant 65 for climate variability and change studies. Future research 66 should therefore focus on integrated measures of cloud 67 parameters and rain variables rather than on instantaneous 68 measures only.

\section{Acknowledgements}

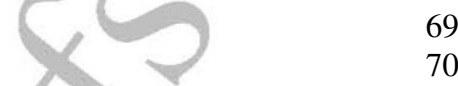

72

The authors would like to thank Annemarie Devis 73 for providing helpful assistance in data interpretation 74 and transformation. The authors greatly appreciated the 75 careful and insightful suggestions and comments of the 76 reviewer which helped to improve the manuscript and 77 data analysis

\section{References}

Adler RF, Negri AJ. 1988. A satellite infrared technique to 82 estimate tropical convective and stratiform rainfall. Journal of Applied Meteorology 27: 30-51, DOI: 10.1175/15200450(1988)027<0030:ASITTE > 2.0.CO;2.

Arnaud Y, Desbois M, Maizi J. 1992. Automatic tracking and characterization of African convective systems on Meteosat pictures. Journal of Applied Meteorology 31: 443-453, DOI: 10.1175/15200450(1992)031<0443:ATACOA > 2.0.CO;2.

Box GEP, Cox DR. 1964. An analysis of transformations. Journal of 88 the Royal Statistical Society, Series B 26: 211-252.

Carvalho LMV, Jones C. 2001. A satellite method to identify 89 structural properties of mesoscale convective systems based on 90 maximum spatial correlation tracking technique (MASCOTTE). 91 Journal of Applied Meteorology 40: 1683-1701, DOI: 10.1175/1520- 92 0450(2001)040<1683:ASMTIS > 2.0.CO;2.

Chong M, Amayenc P, Scialom G, Testud J. 1987. A tropical squall 93 line observed during the COPT 81 experiment in West Africa. 94 Part 1: kinematic structure inferred from Dual-Doppler Radar data. 95 Monthly Weather Review 115(3): 670-694, DOI: 10.1175/1520- 95 0493(1987)115<0670:ATSLOD>2.0.CO;2.

Desbois M, Kayiranga T, Gnamien B, Guessous S, Picon L. 1988. 97 Characterization of some elements of the Sahelian climate and their 98 $\begin{array}{ll}\text { annual variations for July 1983, 1984, and } 1985 \text { from the analysis } & 98 \\ \text { of METEOSAT ISCCP data. Journal of Climate 1: 867-904. } & 99\end{array}$

Feidas H, Cartalis C. 2005. Application of an automated cloud- 100 tracking algorithm on satellite imagery for tracking and mon- 101 itoring small mesoscale convective cloud systems. Interna- 10 tional Journal of Remote Sensing 26(8): 1677-1698, DOI: 102 10.1080/01431160512331338023.

Futyan JM, Del Genio AD. 2007. Deep convective systems evolution 103 over Africa and the Tropical Atlantic. Journal of Climate 20: 104 5041-5058, DOI: 10.1175/JCLI4297.1.

Geerts B, Dejene T. 2005. Regional and diurnal variability of the 106 vertical structure of precipitation systems in Africa based on 107 spaceborne radar data. Journal of Climate 18: 893-916.

Hodges K, Thorncroft C. 1997. Distribution and statistics of the 108 African mesoscale convective systems based on the ISCCP 109 Meteosat Imagery. Monthly Weather Review 125: 2821-2837, DOI: 110 10.1175/1520-0493(1997) $125<2821$ :DASOAM > 2.0.CO;2.

Kidder SQ, Vonder Haar TH. 1995. Satellite Meteorology: an 111 introduction, Academic Press: San Diego, 466.

Klitch MA, Weaver JF, Kelly FP, Vonder Haar TH. 1985. Con- 113 vective cloud climatologies constructed from satellite imagery. 113 Monthly Weather Review 113: 326-337, DOI: 10.1175/1520- 114 0493(1985) $113<0326$ :CCCCFS > 2.0.CO;2.

Laing AG, Carbone R, Levizzani V, Tuttle J. 2008. The propagation 116 and diurnal cycles of deep convection in northern tropical Africa. 116 Quarterly Journal of the Royal Meteorological Society 134: 93-109, 117 DOI: $10.1002 / \mathrm{qj} .194$. 
Laing AG, Fritsch JM. 1993. Mesoscale convective complexes in Africa. Monthly Weather Review 121(8): 2254-2263, DOI: $10.1175 / 1520-0493(1993) 121<2254$ :MCCIA $>2.0 . C O ; 2$.

Laing AG, Fritsch JM, Negri AJ. 1999. Contribution of mesoscale convective complexes to rainfall in Sahelian Africa: estimates from geostationary infrared and passive microwave data. Journal of Applied Meteorology 38(7): 957-964.

Laurent H, D'Amato N, Lebel T. 1998. How important is the contribution of the mesoscale convective complexes to the Sahelian rainfall? Physics and Chemistry of the Earth 23(5-6): 629-633, DOI: 10.1016/S0079-1946(98)00099-8.

Laurent H, Machado L, Morales C, Durieux L. 2002. Characteristics of the Amazonian mesoscale convective systems observed from satellite and radar during the WETAMC/LBA experiment. Journal of the Geophysical Research 107: 1-14, DOI: 10.1029/2001JD000337.

Machado L, Desbois M, Duvel J-P. 1992. Structural characteristics of deep convective systems over Tropical Africa and the Atlantic Ocean. Monthly Weather Review 120: 392-406, DOI: 10.1175/15200493(1992) $120<0392:$ SCODCS $>2.0 . C O ; 2$.

Machado LAT, Laurent H. 2004. The convective system area expansion over Amazonia and its relationships with convective system life duration and high-level wind divergence. Monthly Weather Review 132(3): 714-725.

Machado LAT, Rossow WB, Guedes RL, Walker AW. 1998. Life cycle variations of mesoscale convective systems over the Americas. Monthly Weather Review 126: 1630-1654, DOI: 10.1175/15200493(1998) $126<1630:$ LCVOMC > 2.0.CO;2.

Mathon V, Laurent H. 2001. Life cycle of Sahelian mesoscale convective cloud systems. Quarterly Journal of the Royal Meteorological Society 127: 377-406, DOI: 10.1002/qj.49712757208.

Mathon V, Laurent H, Lebel T. 2002. Mesoscale convective system rainfall in the Sahel. Journal of Applied Meteorology 41: 1081-1092, DOI: 10.1175/1520-0450(2002)041<1081:MCSRIT>2.0.CO;2.

McPherson G. 1990. Statistics in Scientific Investigation: Its Basis, Application, and Interpretation, Springer-Verlag: New York, 666.

Mohr K. 2004. Interannual, monthly, and regional variability in the wet season diurnal cycle of precipitation in Sub-Saharan Africa. Journal of Climate 17: 2441-2453.
NASDA Earth Observation Centre. 2001. TRMM Data Users Handbook, Earth Observation Center, National Space Development Agency of Japan: Japan, 226.

Nesbitt SW, Zipser EJ, Cecil DJ. 2000. A census of precipitation features in the Tropics using TRMM: radar, ice scattering and lightning observations. Journal of Climate 13: 4087-4106.

Nuret M, Chong M. 1998. Characteristics of heat and moisture budgets of a mesoscale convective system observed during TOGACOARE. Ouarterly Journal of the Royal Meteorological Society 124: 1163-1181, DOI: 10.1002/qj.49712454807.

Sakia RM. 1992. The Box-Cox transformation technique: a review. The Statistician 41: 169-178.

Schrage JM, Fink AH, Ermert V, Ahlonsou ED. 2006. Three MCS cases occurring in different synoptic environments in the subsahelian wet zone during the 2002 West African monsoon. Journal of Atmospheric Sciences 63(9): 2369-2382, DOI: 10.1175/JAS3757.1.

Schröder M, König M, Schmetz J. 2009. Deep convection observed by the spinning enhanced visible and infrared imager on board Meteosat 8: spatial distribution and temporal evolution over Africa in summer and winter 2006,. Journal of Geophysical Research 114: D05109, DOI: $10.1029 / 2008 J D 010653$.

Schumacher C, Houze RAJ. 2004. Mesoscale convective systems over sub-Saharan Africa and the Tropical East Atlantic. Conference paper: $26^{\text {th }}$ Conference on Hurricanes and Tropical Meteorology, American Meteorological Society. Miami, USA.

Sui C-H, Lau K-M, Takayabu YN, Short DA. 1997. Diurnal variations in tropical oceanic cumulus convection during TOGA COARE. Journal of Atmospheric Sciences 54: 639-655.

Tomasini M, Lafore J-P, Piriou C, Roca R, Ramage K, Laurent H, Morel C, Senesi S. 2006. ATLAS on a climatology of West African mesoscale convective systems (Version 1), Technical Note, AMMA Campaign Archive. France.

Wilcox EM. 2003. Spatial and temporal scales of precipitation tropical cloud systems in satellite imagery and the NCAR CCM3. Journal of Climate 16: 3545-3559, DOI: 10.1175/15200442(2003)016<3545:SATSOP $>2.0$.CO;2.

Zipser EJ, Cecil DJ, Liu C, Nesbitt SW, Yorty DP. 2006. Where are the most intense thunderstorms on earth? Bulletin of the American Meteorological Society 87: 1057-1071.
60

61

62

63

64

65 
QUERIES TO BE ANSWERED BY AUTHOR

IMPORTANT NOTE: Please mark your corrections and answers to these queries directly onto the proof at the relevant place. Do NOT mark your corrections on this query sheet.

Queries from the Copyeditor:

AQ1 Please confirm if the abbreviations 'NASA and WV' need to be spelt out. If yes, please provide the expansions.

AQ2 Figures 1 to 8 are of low clarity. Kindly provide better replacement figures or confirm if we may use the existing ones.

AQ3 These figure(s) 2, 6 has been supplied in colour. There is a charge to print the figure(s) in colour, however figure(s) will be published in colour online free of cost. The first colour printed page will be $£ 250$ and each colour printed page thereafter will be $£ 150$ (per page). Please confirm if this figure is to be reproduced in (a) colour in print, (b) colour online only if suitable (at no charge to author) or (c) black and white in both cases (please provide new figure). Colour will be invoiced when the article is published in print. For the options (b) and (c), could you kindly identify and make any necessary text amendments that may need to be made in the caption or text with regard to this change.

AQ4 Please check the edit made in the caption of Table IV. 


\section{USING E-ANNOTATION TOOLS FOR ELECTRONIC PROOF CORRECTION}

\section{Required Software}

Adobe Acrobat Professional or Acrobat Reader (version 7.0 or above) is required to e-annotate PDFs.

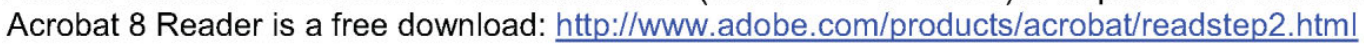

Once you have Acrobat Reader 8 on your PC and open the proof, you will see the Commenting Toolbar (if it does not appear automatically go to Tools>Commenting>Commenting Toolbar). The Commenting Toolbar looks like this:

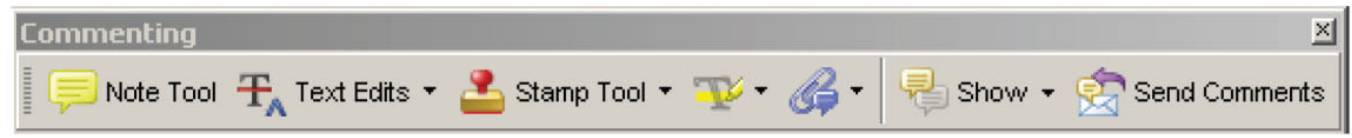

If you experience problems annotating files in Adobe Acrobat Reader 9 then you may need to change a preference setting in order to edit.

In the "Documents" category under "Edit - Preferences", please select the category 'Documents' and change the setting "PDF/A mode:" to "Never".

\section{-PDF/A View Mode}

View documents in PDF/A mode: Wever

\section{Note Tool - For making notes at specific points in the text}

Marks a point on the paper where a note or question needs to be addressed.

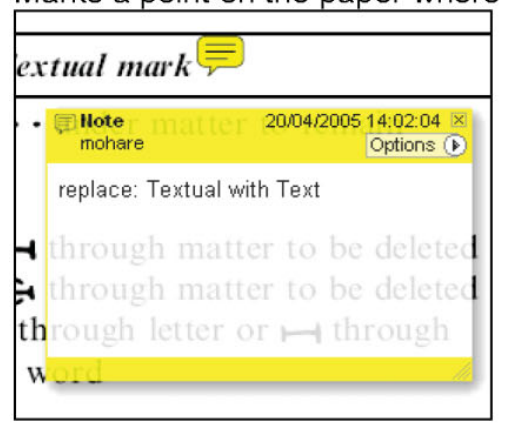

\section{How to use it:}

1. Right click into area of either inserted text or relevance to note

2. Select Add Note and a yellow speech bubble symbol and text box will appear

3. Type comment into the text box

4. Click the $X$ in the top right hand corner of the note box to close.

\section{Replacement text tool - For deleting one word/section of text and replacing it}

Strikes red line through text and opens up a replacement text box.

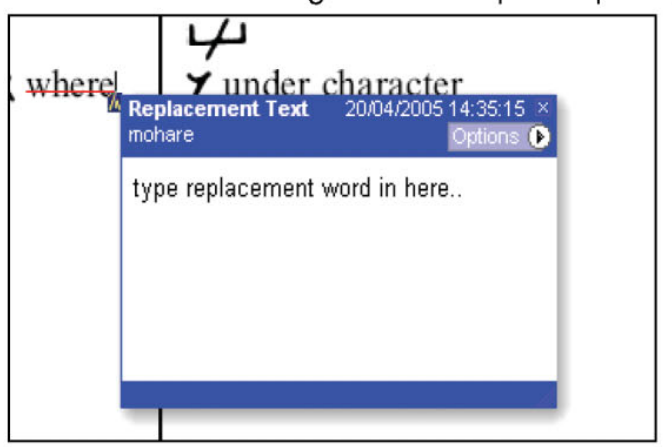
How to use it:
1. Select cursor from toolbar
2. Highlight word or sentence
3. Right click
4. Select Replace Text (Comment) option
5. Type replacement text in blue box
6. Click outside of the blue box to close

Cross out text tool - For deleting text when there is nothing to replace selection Strikes through text in a red line.

\begin{tabular}{|l|}
\hline substitute part of one or \\
more word(s) \\
Change to italics| \\
Change to capitals \\
Change to small capitals \\
\hline
\end{tabular}
How to use it:
1. Select cursor from toolbar
2. Highlight word or sentence
3. Right click
4. Select Cross Out Text 
Approved tool - For approving a proof and that no corrections at all are required.

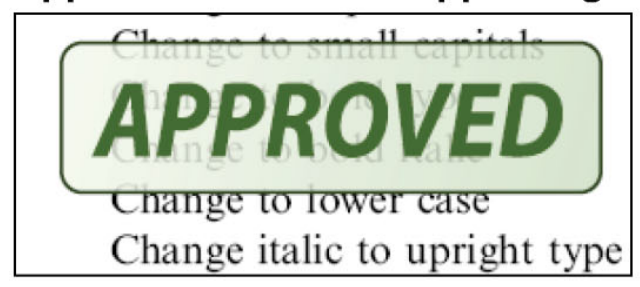

\section{How to use it:}

1. Click on the Stamp Tool in the toolbar

2. Select the Approved rubber stamp from the 'standard business' selection

3. Click on the text where you want to rubber stamp to appear (usually first page)

Highlight tool - For highlighting selection that should be changed to bold or italic. Highlights text in yellow and opens up a text box.

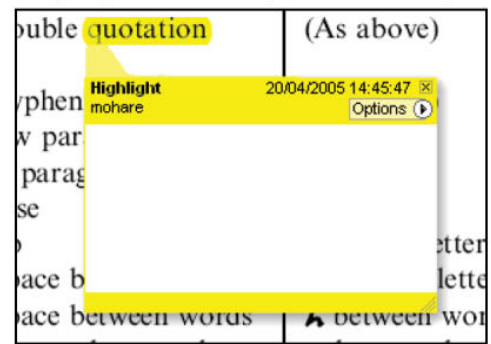

\section{How to use it:}

1. Select Highlighter Tool from the commenting toolbar

2. Highlight the desired text

3. Add a note detailing the required change

Attach File Tool - For inserting large amounts of text or replacement figures as a files. Inserts symbol and speech bubble where a file has been inserted.

\begin{tabular}{|l|}
\hline matter to be changed \\
matter to be clapged \\
matter to be changed \\
matter to be changed
\end{tabular}

\section{How to use it:}

1. Click on paperclip icon in the commenting toolbar

2. Click where you want to insert the attachment

3. Select the saved file from your PC/network

4. Select appearance of icon (paperclip, graph, attachment or tag) and close

\section{Pencil tool - For circling parts of figures or making freeform marks}

Creates freeform shapes with a pencil tool. Particularly with graphics within the proof it may be useful to use the Drawing Markups toolbar. These tools allow you to draw circles, lines and comment on these marks.

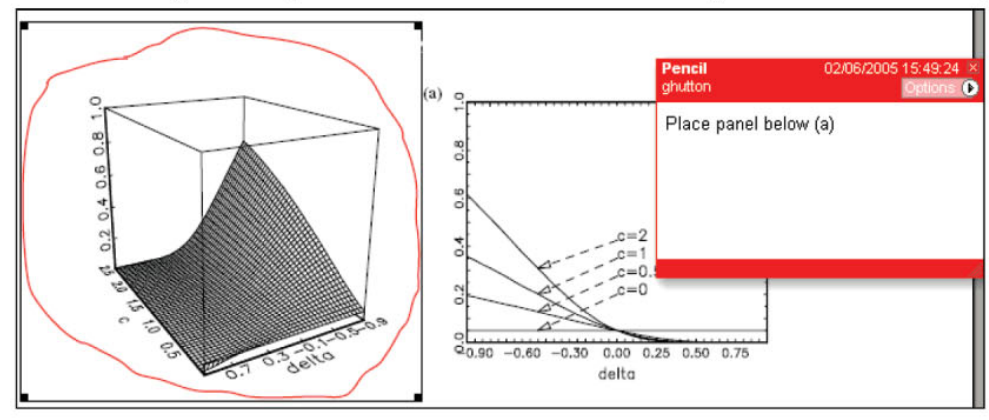

\section{How to use it:}

1. Select Tools $>$ Drawing Markups $>$ Pencil Tool

2. Draw with the cursor

3. Multiple pieces of pencil annotation can be grouped together

4. Once finished, move the cursor over the shape until an arrowhead appears and right click

5. Select Open Pop-Up Note and type in a details of required change

6. Click the $X$ in the top right hand corner of the note box to close. 
Help

For further information on how to annotate proofs click on the Help button to activate a list of instructions:

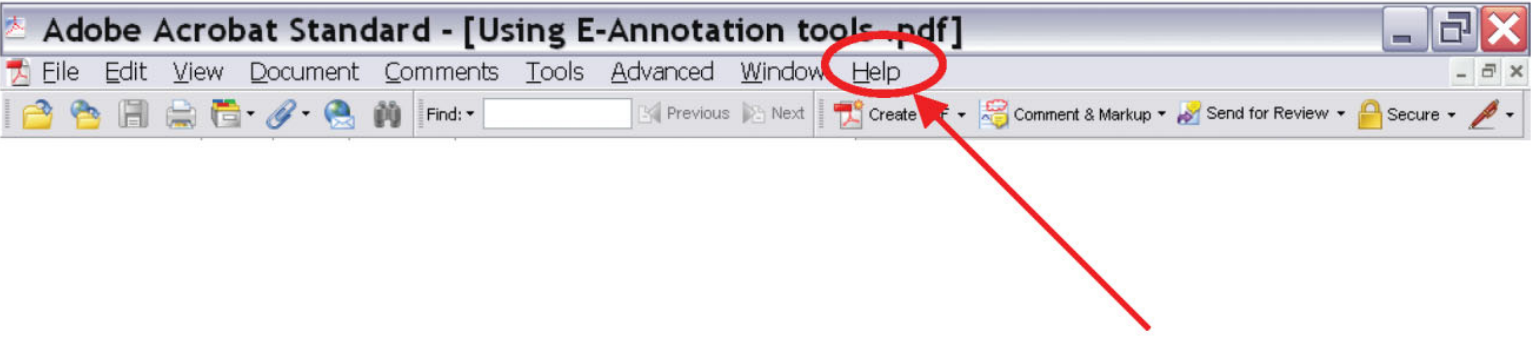

